\title{
Tuning the outcome of enzyme-mediated dynamic cyclodextrin libraries to enhance template effects
}

\author{
Larsen, Dennis; Beeren, Sophie
}

Published in:

Chemistry - A European Journal

Link to article, DOI:

10.1002/chem.202001076

Publication date:

2020

Document Version

Peer reviewed version

Link back to DTU Orbit

\section{Citation $(A P A)$ :}

Larsen, D., \& Beeren, S. (2020). Tuning the outcome of enzyme-mediated dynamic cyclodextrin libraries to enhance template effects. Chemistry - A European Journal, 26(48), 11032-11038.

https://doi.org/10.1002/chem.202001076

\section{General rights}

Copyright and moral rights for the publications made accessible in the public portal are retained by the authors and/or other copyright owners and it is a condition of accessing publications that users recognise and abide by the legal requirements associated with these rights.

- Users may download and print one copy of any publication from the public portal for the purpose of private study or research.

- You may not further distribute the material or use it for any profit-making activity or commercial gain

- You may freely distribute the URL identifying the publication in the public portal

If you believe that this document breaches copyright please contact us providing details, and we will remove access to the work immediately and investigate your claim. 


\section{Chemistry}

A European

Journal

\section{Chemistry Europe}

European Chemical Societies Publishing

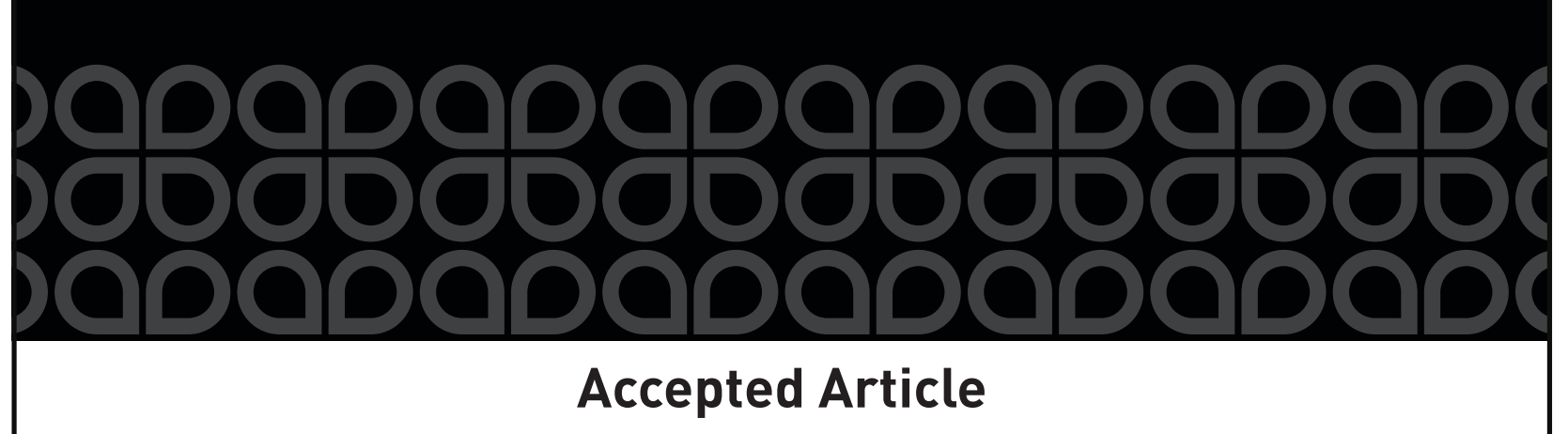

Title: Tuning the outcome of enzyme-mediated dynamic cyclodextrin libraries to enhance template effects

Authors: Dennis Larsen and Sophie R. Beeren

This manuscript has been accepted after peer review and appears as an Accepted Article online prior to editing, proofing, and formal publication of the final Version of Record (VoR). This work is currently citable by using the Digital Object Identifier (DOI) given below. The VoR will be published online in Early View as soon as possible and may be different to this Accepted Article as a result of editing. Readers should obtain the VoR from the journal website shown below when it is published to ensure accuracy of information. The authors are responsible for the content of this Accepted Article.

To be cited as: Chem. Eur. J. 10.1002/chem.202001076

Link to VoR: https://doi.org/10.1002/chem.202001076 
WILEY-VCH

\section{Tuning the outcome of enzyme-mediated dynamic cyclodextrin libraries to enhance template effects}

\author{
Dennis Larsen, ${ }^{[a]}$ and Sophie R. Beeren*[a]
}

\begin{abstract}
Enzyme-mediated dynamic combinatorial chemistry combines the concept of thermodynamically controlled covalent selfassembly with the inherent biological relevance of enzymatic transformations. We explore a system of interconverting cyclodextrins wherein the glycosidic linkage is rendered dynamic by the action of cyclodextrin glucanotransferase (CGTase). We report that external factors, such as $\mathrm{pH}$, temperature, solvent, and salinity can be modulated to influence the composition of the dynamic cyclodextrin library. Dynamic libraries of cyclodextrins (CDs) could be obtained in wide ranges of $\mathrm{pH}(5.0-9.0)$, temperature $\left(5-37^{\circ} \mathrm{C}\right)$, and salinity (up to $7.5 \mathrm{M} \mathrm{NaNO}_{3}$ ), and with high organic solvent content (50\% by volume of ethanol), showing that enzyme-mediated dynamic systems can be robust and not limited to physiological conditions. Furthermore, we demonstrate how strategic choice of reaction conditions can enhance template effects, in this case, to achieve highly selective production of $\alpha-C D$, an otherwise challenging target due to competition from the structurally similar $\beta-C D$.
\end{abstract}

\section{Introduction}

Dynamic combinatorial chemistry has evolved into a powerful tool to explore molecular self-assembly and systems chemistry behavior, and to identify macrocyclic hosts for small molecules or ligands for biomacromolecules. ${ }^{[1]}$ Dynamic covalent reactions have been exploited to develop smart materials, ${ }^{[2]}$ to generate self-replicating systems, ${ }^{[3]}$ and have enabled access to complicated macrocycles such as (hemi)cucurbit[n]urils, biotin[6]urils, cryptates and larger nano-rings. ${ }^{[4]}$ Significant effort has been exerted to develop synthetic dynamic systems that mimic biological dynamic systems. Dynamic combinatorial libraries (DCLs) using biomimetic building blocks ${ }^{[5]}$ have been explored and "biocompatible" reversible chemistries that work in water under biologically relevant conditions have been targeted, for example, by using thiol exchange at neutral $\mathrm{pH}^{[6]}$ or by developing catalysts for hydrazone and oxime exchange at

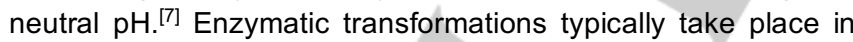
water at moderate temperature and close to neutral $\mathrm{pH}$, and act on inherently biologically relevant building blocks (i.e. biomonomers such as amino acids, nucleotides, or carbohydrates). Despite the promises of applying enzymes to make "biocompatible" or biomimetic dynamic systems, less than a handful of enzyme-enabled dynamic systems have been reported to date.

[a] Dr. Dennis Larsen, Prof. Dr. Sophie R. Beeren

Department of Chemistry

Technical University of Denmark

Kemitorvet 207, DK-2800 Kongens Lyngby, Denmark

E-mail: sopbee@kemi.dtu.dk

Supporting information for this article is given via a link at the end of the document.
The group of Venton reported the first example of an enzyme-mediated $\mathrm{DCL}$, when they employed trypsin to make a small dynamic library of oligopeptides. ${ }^{[8]}$ Brown and co-workers reported the use of a sialic acid aldolase to produce libraries of sialic acid analogues, ${ }^{[9]}$ and Flitsch and co-workers demonstrated protease enabled amine acyl exchange on gold surfaces. ${ }^{[10]}$ Most recently the Ulijn lab have developed protease-enabled dynamic peptide libraries employed towards the formation of supramolecular nanostructures. ${ }^{[11]}$

We recently reported how the enzyme cyclodextrin glucanotransferase (CGTase) can be used to afford a dynamic system of interconverting linear and cyclic oligomers of glucose connected by $\alpha(1 \rightarrow 4)$ glycosidic bonds (Figure 1a). ${ }^{[12]}$ CGTase catalyses two reactions: both reversible inter- and intramolecular transglycosylations to yield linear or cyclic $\alpha$-glucans (cyclodextrins), respectively; and slow hydrolysis (Figure 1b). The dynamic system consists primarily of the three macrocyclic native cyclodextrins (CDs) $\alpha-C D, \beta-C D$, and $\gamma-C D$ (with 6,7 , and 8 glucopyranose units, respectively) which are formed in an approximately 35/60/5 ratio. Due to CGTase's kinetic preference for macrocyclisation, the CDs are formed rapidly in a kinetically trapped subsystem, which behaves as a transient DCL over which there is pseudo thermodynamic control. Slow background hydrolysis means that eventually, over many days, all $\alpha$-glucans in the system are converted to glucose. ${ }^{[12 a]}$

CDs are one of the most important and well-studied macrocyclic structures in supramolecular chemistry, ${ }^{[13]}$ with applications in, amongst others, the food, cosmetics and pharmaceutical industries where their role as water soluble hosts for hydrophobic guests is exploited. ${ }^{[14]}$ We showed that addition of templates (guests) that bind selectively to specific CDs can alter the CD distribution in CGTase-mediated cyclodextrin DCLs to produce each of the three CDs with $89-99 \%$ selectivity. Furthermore, we demonstrated that templates that bind to even larger CDs, e.g. $\delta-C D$ or $\varepsilon-C D$ with 9 and 10 glucose units, respectively, can be employed to produce these large-ring $\mathrm{CDs}$ with hitherto unmatched selectivity. ${ }^{[12 a]}$

The glycosidic bond can be made dynamic by the action of CGTase under mild conditions ( $\mathrm{pH} 7.5$ at room temperature), but during our initial screening for optimal conditions for the enzymatic reactions, we noticed that CGTase was remarkably resilient to changes in conditions such as $\mathrm{pH}$, salinity, solvent composition and presence of templates. While the influence of some of these parameters on CGTase activity, CD yield and selectivity in kinetically controlled regimes relevant for industrial production has been investigated, ${ }^{[15]}$ we were interested to explore how such (non-template) external factors would affect the dynamicity and equilibrium distribution of $\mathrm{CDs}$ in our dynamic system. We present here how tuning of $\mathrm{pH}$, temperature, building block concentration, solvent composition and salinity can be employed to control the equilibrium CD distribution in CGTase-mediated DCLs and enhance template effects. 
a

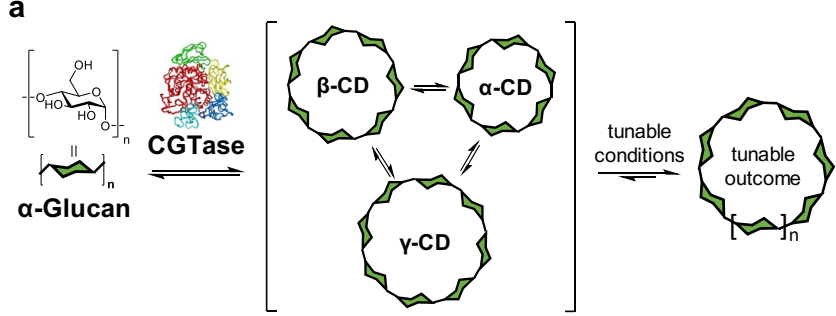

b
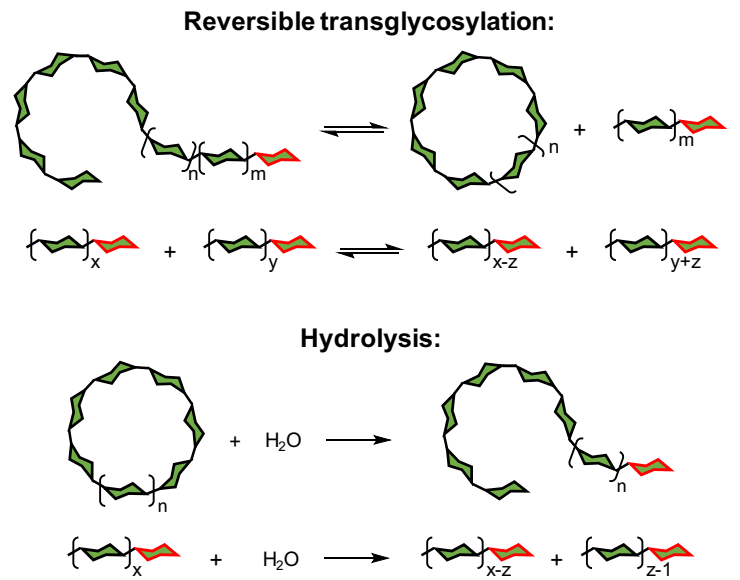

Figure 1. (a) Cyclodextrin glucanotransferase (CGTase) acts on $\alpha$-glucans to generate dynamic combinatorial libraries (DCLs) of interconverting cyclodextrins. Changing the $\mathrm{pH}$, temperature, concentration, solvent composition and salinity allows control over the outcome of the enzymemediated DCL. (b) The reactions catalysed by CGTase. Transglycosylation is reversible and includes both an intramolecular reaction that leads to $C D$ formation (macrocyclisation) and an intermolecular reaction that can shorten and elongate linear $\alpha$-glucans (scrambling). Hydrolysis leads to the formation of a new reducing-end glucose unit (highlighted in red), which cannot be reincorporated into a macrocycle. $n, m=[0,1,2, \ldots] ; x, y, z=[1,2,3, \ldots]$.

\section{Results and Discussion}

\section{The influence of temperature on cyclodextrin DCLs}

To explore the influence of temperature on the distribution of products in cyclodextrin DCLs and the overall CD yield, CGTasemediated dynamic cyclodextrin systems were prepared at $5{ }^{\circ} \mathrm{C}$, $22^{\circ} \mathrm{C}$ and $37^{\circ} \mathrm{C}$. CGTase from Bacillus macerans $(50 \mu \mathrm{L}$ of a ca. $12 \mathrm{mg} / \mathrm{ml}$ stock solution per $1 \mathrm{~mL}$ of reaction mixture) was allowed to act on maltohexaose $(\mathbf{G 6})(10 \mathrm{mg} / \mathrm{mL})$ in sodium phosphate buffer $(50 \mathrm{mM})$ at $\mathrm{pH} 7.5$ and the formation and disappearance of the various cyclic and linear $\alpha$-glucans was monitored as the dynamic system evolved over time. (Figure $2 a$ and Figure S3 in the Supporting Information). Analysis was achieved using high performance liquid chromatography with evaporative light scattering detection (HPLC-ELS), which enables detection of the otherwise chromophore- and fluorophore-less oligosaccharides.

The industrial production of CDs via the action of CGTase is typically performed at relatively high temperature $\left(50-70^{\circ} \mathrm{C}\right)^{[15]}$ and indeed an optimal reaction temperature of $60{ }^{\circ} \mathrm{C}$ has been reported. ${ }^{[15 c]}$ In preliminary experiments, however, we found that while initially highly active at $50{ }^{\circ} \mathrm{C}$, CGTase was rendered effectively inactive after 1 day at such a high temperature, both at $\mathrm{pH} 5.5$ and $\mathrm{pH} 7.5$ (Sections S2 and S3 in the Supporting Information). To establish an enzyme-mediated DCL we required long-term enzyme stability, at least long enough that a thermodynamically-controlled distribution of library members can form. Fortunately CGTase activity could be retained lowering the temperature to $37^{\circ} \mathrm{C}$ (Section S3 in the Supporting Information). Furthermore we have recently shown that it is possible to establish a dynamic system of linear and cyclic $\alpha$-glucans at $25^{\circ} \mathrm{C}$ that stays dynamic for at least 31 days. ${ }^{[12 a]}$

Figure 2a shows a representative chromatogram of the $\alpha$ glucan mixture formed by CGTase action on $\mathbf{G 6}$ at $37^{\circ} \mathrm{C}$ after 60 minutes. Linear $\alpha$-glucans $\mathbf{G 1 - G 8}$ (seen as split peaks due to pairs of anomers) and, $\alpha-, \beta-$, and $\gamma-C D$ are clearly identifiable. At $37^{\circ} \mathrm{C}$ a steady distribution of the different $\mathrm{CDs}$ is observed after approximately 30 minutes, when a pseudo thermodynamic equilibrium distribution of cyclodextrins is obtained (Figure 2c). As the temperature was reduced, the approach to equilibrium was slower, but a steady CD distribution was achieved within two hours even at $5{ }^{\circ} \mathrm{C}$. By analysing the rate of consumption of hydrolysable glucose monomer units (all glucose units except the reducing ends of linear library members) and the time taken to reach the half maximum $C D$ yield, we estimated apparent rate constants for $\mathrm{CD}$ formation $\left(k_{\mathrm{CD}}\right)$ and the hydrolysis side reaction $\left(k_{\mathrm{h}}\right)$ (Section S4.1 and Figures S4-S5 in the Supporting Information). Both $k_{\mathrm{CD}}$ and $k_{\mathrm{h}}$ decreased upon lowering the temperature (Figure S6 in the Supporting Information) and consequently temperature variation had very little influence upon the total $C D$ yield (Figure 2 grey lines).

We noticed, however, a small but significant change in the equilibrium $C D$ distribution as a function of temperature (Figure $2 b)$. The relative $\alpha-C D$ concentration at equilibrium increased with higher reaction temperature, while the relative yield of both $\beta-C D$ and $\mathrm{y}-\mathrm{CD}$ decreased. As there is an inherently higher entropic penalty for the formation of larger CDs, this result is in line with the notion that entropic factors play a larger role in the overall free energy of the system at higher temperatures. Control over reaction temperature within the determined dynamic range $\left(5^{\circ} \mathrm{C}\right.$ to $37^{\circ} \mathrm{C}$ ) could thus be exploited to target specific $\mathrm{CD}$ products.

\section{The influence of $\mathrm{pH}$}

To gain an overview of the influence of $\mathrm{pH}$ on enzyme activity, as well as the dynamics and the equilibrium CD distribution in the CGTase-mediated DCLs, we set up a series of libraries started from maltohexaose $(\mathbf{G} 6)$ at $\mathrm{pH} 4.0-9.0\left(10 \mathrm{mg} / \mathrm{mL}, 22^{\circ} \mathrm{C}, 50 \mathrm{mM}\right.$ buffer, either sodium citrate, sodium phosphate or tris(hydroxymethyl)aminomethane (tris)). We monitored the formation of cyclic and linear $\alpha$-glucans over at least 60 hours (Figures S7 and S8 in the Supporting Information).

Figures $3 a$ and $3 b$ compare the extent of CD formation after 20 minutes and the degree of hydrolysis from 24 hours to 60 hours in libraries prepared at different $\mathrm{pH}$, as a measure of initial and continuing enzyme activity, respectively. At pH 4.0 and 4.5, CGTase became inactive within less than one day and an 
a

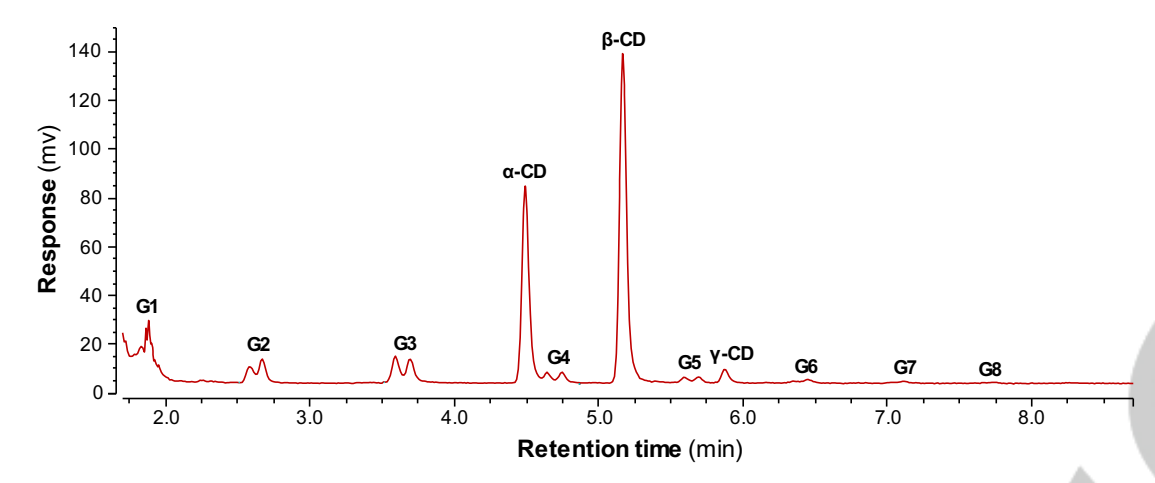

C

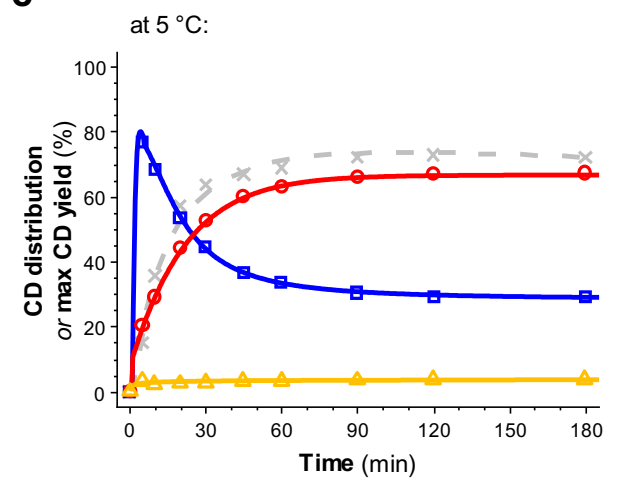

b

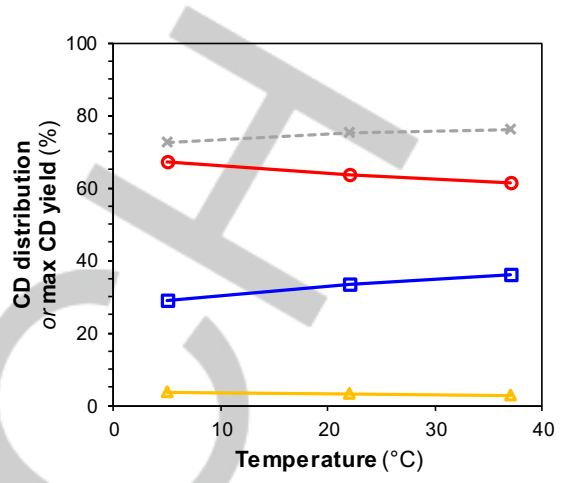

at $37^{\circ} \mathrm{C}$ :

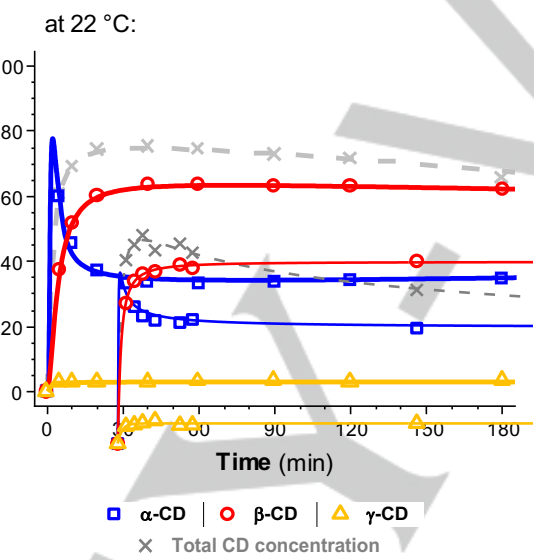

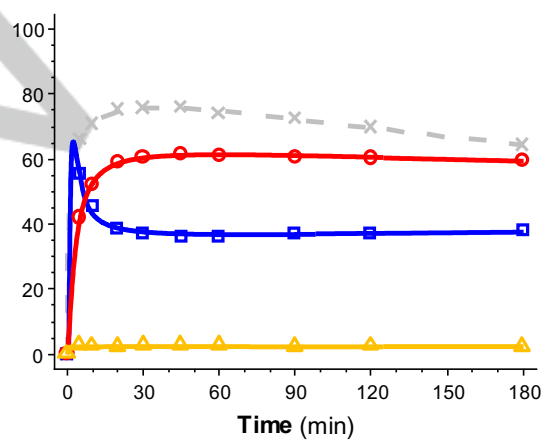

Figure 2. Temperature screening. (a) Representative chromatogram (HPLC-ELS) showing typical distribution of $\alpha$-glucans at pseudo-equilibrium formed when CGTase acts on $\mathbf{G 6}(10 \mathrm{mg} / \mathrm{mL})$ in sodium phosphate buffer $(50 \mathrm{mM}, \mathrm{pH} 7.5)$ (from experiment at $37^{\circ} \mathrm{C}$ after 60 minutes of reaction). (b) Equilibrium CD distribution and highest $C D$ yield as a function of temperature. (c) $C D$ distribution and total $C D$ yield monitored over the first three hours of reaction at indicated temperature.

equilibrium distribution of CDs was never reached. The reactions conducted at $\mathrm{pH}$ 5-8 reached a steady $\mathrm{CD}$ distribution within ca. 1 to $1 \frac{1}{2}$ hours, while the libraries at $\mathrm{pH} 8.5$ and $\mathrm{pH} 9.0$, required up to ca. 3 and 6 hours, respectively. It should be noted that significant build-up of byproducts occurred in reactions in tris buffer after several days due to a slow reaction with the buffer itself (Section S5.1 in the Supporting Information).

The equilibrium distributions of $\alpha-, \beta-$, and $\gamma-C D$ at different $\mathrm{pH}$ values are plotted in Figure $3 \mathrm{c}$. The ratio of $\mathrm{CDs}$ is relatively constant over the entire $\mathrm{pH}$ range $5.0-9.0$, which is consistent with the expectation that $\mathrm{pH}$ should not influence relative $\mathrm{CD}$ stability. A slight increase in the $\alpha-C D$ content was seen upon switching from citrate buffer to phosphate buffer, which might be explained by the higher ionic strength of phosphate buffers compared to citrate buffers (salt effects are discussed below). Overall, we found that the remarkable $\mathrm{pH}$ stability of CGTase means that we can prepare truly dynamic systems of CDs over a wide range of $\mathrm{pH}$ (5.0 to 9.0). This versatility can be an advantage because it broadens both the selection of templates that can be employed, and the different chemistries that could be explored alongside CGTase action in more complex dynamic systems.

\section{Concentration effects}

The equilibrium distribution of oligomeric species in DCLs is dependent on the building block concentration. ${ }^{[1 a, 16]}$ To examine the effect of total sugar concentration on the equilibrium $C D$ distribution and total $C D$ yields, we set up and monitored the action of CGTase on $1-40 \mathrm{mg} / \mathrm{mL}$ of $\mathbf{G 6}$ in phosphate buffer at $\mathrm{pH} 7.5$ (Figures S11 and S12 in the Supporting Information). The equilibrium $C D$ distributions as a function of starting concentration of $\mathbf{G 6}$ are shown in Figure 4a. As expected, the proportion of larger CDs ( $\beta$ - and $\gamma$-CD) goes up as the total sugar concentration increases, since larger macrocycles are favoured at higher building block concentrations.

Figure $4 a$ also shows the maximum $C D$ yield obtained from different starting concentrations of $\mathbf{G 6}$. The maximum $C D$ yield was found to increase upon increasing the concentration of $\mathbf{G 6}$ from 1 to $5 \mathrm{mg} / \mathrm{mL}$ but decrease upon moving to even higher $\mathbf{G} 6$ concentrations. As the concentration increases the rate of intermolecular transglycosylation (scrambling) will increase relative to both the rates of hydrolysis and intramolecular transglycosylation (macrocyclization). A relatively slower rate of hydrolysis will favour high CD yields, but a relatively slower rate of macrocyclisation will lead to low CD yields. It appears that 
a

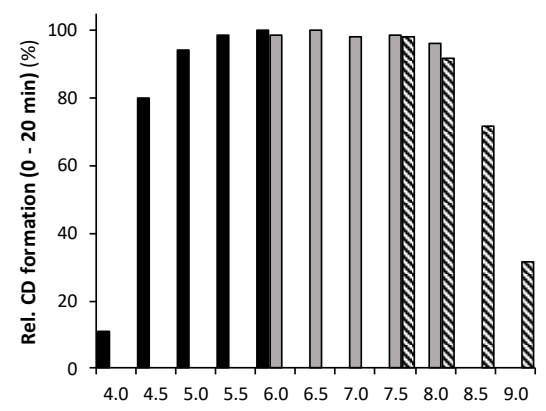

$\mathrm{pH}$ b

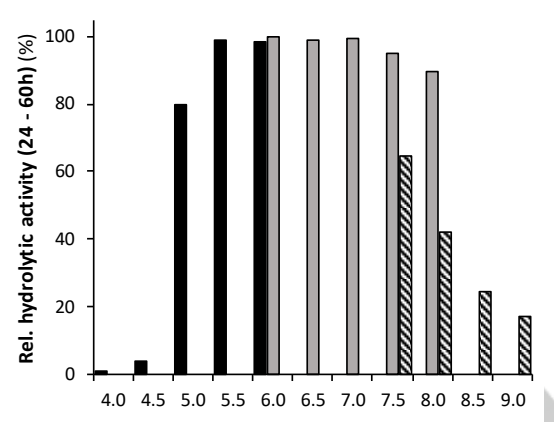

pH

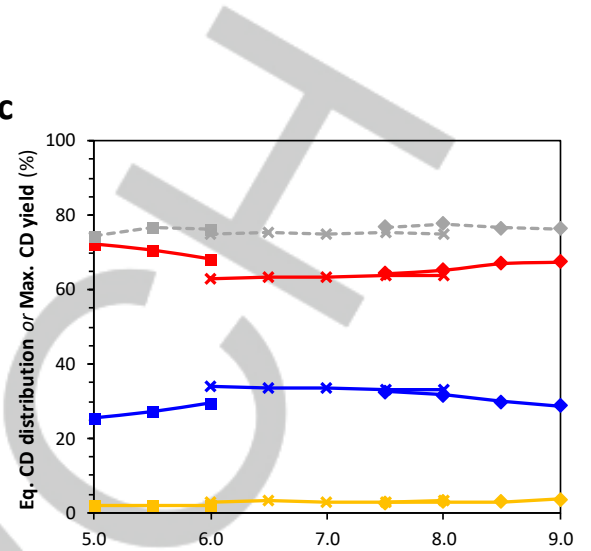

pH

Buffer:
- Citrate $\quad \square$ Phosphate $\quad$ S Tris

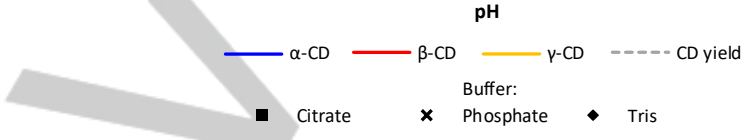

Figure 3. $\mathrm{pH}$ screening. (a) Activity of CGTase at different $\mathrm{pH}$ and in different buffers quantified as the relative $\mathrm{CD}$ formation over the first 20 minutes of reaction time. (b) Activity of CGTase after 24 hours at different $\mathrm{pH}$ and in different buffers quantified as the amount of hydrolysis over the following 36 hours. (c) Equilibrium $\mathrm{CD}$ distribution and maximum $\mathrm{CD}$ yield as a function of buffer and $\mathrm{pH}$. Conditions: $\mathbf{G} 6(10 \mathrm{mg} / \mathrm{mL})$ in indicated buffer $(50 \mathrm{mM})$ at indicated $\mathrm{pH}$ treated with $\mathrm{CGTase}$ at room temperature.

a glucan concentration of approximately $5 \mathrm{mg} / \mathrm{mL}$ is where a balance between hydrolysis and excessive intermolecular transglycosylation leads to the highest CD yield.

The relatively higher rate of hydrolysis compared to intermolecular transglycosylation at low glucan concentrations meant that the lifetime of the dynamic system decreased dramatically with decreasing concentration following an apparently exponential order in relation to $\mathbf{G 6}$ starting concentration (Figure $4 \mathrm{~b}$ ). Here, we defined the lifetime of the system as the half-life $\left(t_{1} / 2\right)$ of the hydrolysis reaction (Section S6.1 in the Supporting Information). At $t \frac{1}{2}$, half of the glucose units in the dynamic system have been converted to reducing ends, and can no longer be used to form CDs. This value is therefore directly related to the lifetime of the transient $D C L$ of $C D s$. While $5 \mathrm{mg} / \mathrm{mL}$ starting concentration of $\mathbf{G} 6$ is optimal to give high CD yields, the lifetime of the transient $D C L$ is rather short. We suggest an optimal glucan concentration of ca. $10-20 \mathrm{mg} / \mathrm{mL}$ for these CGTase-mediated dynamic cyclodextrin systems.

\section{The influence of ethanol as organic co-solvent}

It has been reported that addition of polar organic solvents can enhance the yield and selectivity of CGTase-catalysed CD production from starch. ${ }^{[17,18]}$ However, whether these effects are due to solvent influences on CGTase activity, substrate selectivity, formation of inclusion complexes or kinetics has remained unclear, in part, because many studies have been based on single timepoint analysis of reactions without taking into consideration the complexity and dynamic nature of the CGTase-mediated cyclodextrin system. To explore the effect of an organic co-solvent on our dynamic system of CDs, we set up a series of reactions starting from $\mathbf{G 6}(10 \mathrm{mg} / \mathrm{mL})$ in phosphate buffer $(50 \mathrm{mM}, \mathrm{pH} 7.5)$ a

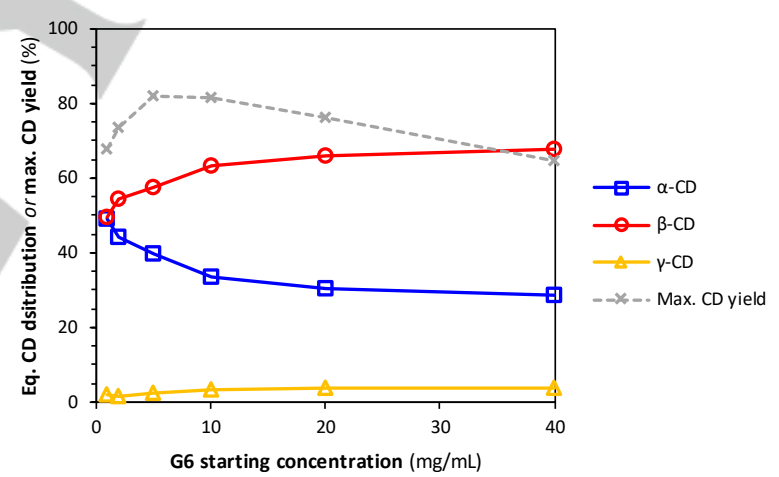

b

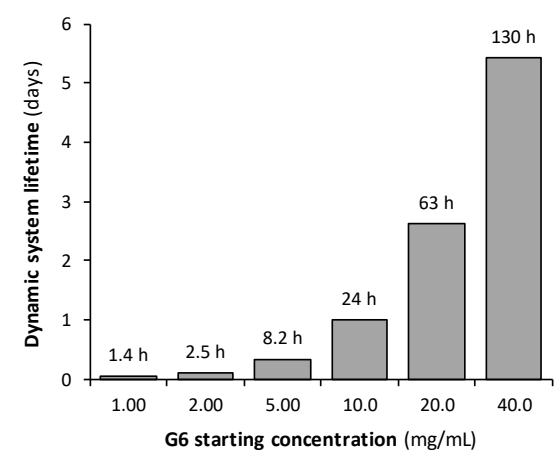

Figure 4. Concentration effects. (a) Equilibrium $C D$ distribution and maximum CD yield as a function of $\mathbf{G 6}$ starting concentration. (b) Lifetimes of dynamic systems as a function of $\mathbf{G 6}$ starting concentration. The lifetime is defined as the half-life of hydrolysis assuming pseudo-first order kinetics. Conditions: G6 at indicated concentration in sodium phosphate buffer $(50 \mathrm{mM}, \mathrm{pH} 7.5)$ treated with CGTase at room temperature. 
a

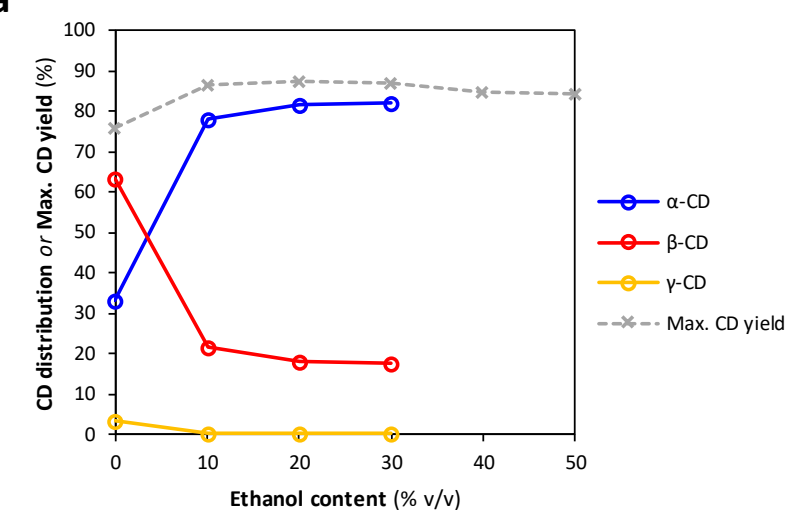

b

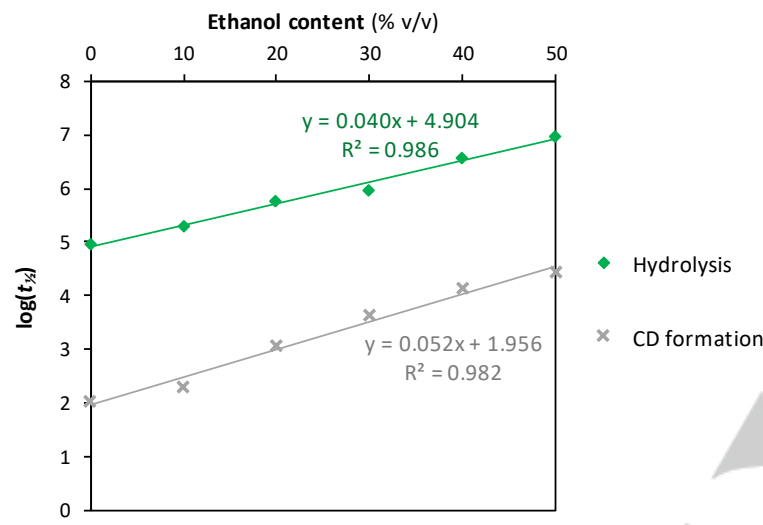

Figure 5. Ethanol as co-solvent. (a) CD distribution at equilibrium and highest CD yields when CGTase acts on $\mathbf{G 6}$ in the presence of different amounts of ethanol as co-solvent. The reactions with 40 and $50 \%$ ethanol by volume did not reach equilibrium within 72 hours. (b) Change in half-lives $\left(t / \frac{1}{2}\right)$ of the hydrolysis and CD formation reactions catalysed by CGTase as a function of the ethanol content (see ESI for details). Conditions: G6 in sodium phosphate buffer ( $25 \mathrm{mM}, \mathrm{pH} 7.5)$ treated with CGTase at room temperature.

with $0-50 \%$ by volume of ethanol and monitored the total $C D$ yield and CD distribution over a period of 72 hours (Figures S14 and S15 in the Supporting Information).

In all cases, the addition of ethanol had a stabilising effect on $\alpha-C D$ (Figure $5 a$ ), which is consistent with previously reported higher $\alpha-C D$ yields observed in the presence of ethanol. ${ }^{[18]}$ The equilibrium $C D$ distribution shifted dramatically from ca. $35 \% \alpha-$ $\mathrm{CD}$ in aqueous buffer to ca. $80 \% \alpha-C D$ even in the presence of only $10 \%$ ethanol by volume (Figure $5 \mathrm{a}$ ). The sharp change in composition with any amount of ethanol suggests an actual binding event rather than a solvent effect (i.e. change in solvent polarity). $\alpha-C D$ has a reported weak binding affinity (ca. $K_{a}=10$ $\mathrm{M}^{-1}$ ) towards ethanol in water, with no reported affinities for $\beta$ - or $\gamma$-CD towards ethanol. ${ }^{[13,19]}$ However, the continued presence of $20 \% \beta-C D$ in the $D C L$, despite such high concentrations of ethanol, indicates that a weak interaction must exist between $\beta$ $\mathrm{CD}$ and ethanol. Using the DCLfit software, developed by Otto to extract binding constants directly from equilibrium product distributions in templated DCLs, ${ }^{[20]}$ we estimate that $\beta-C D$ binds ethanol roughly $6-7$-fold weaker than $\alpha$-CD (Section S7.1 in the Supporting Information)

In our experiments, and consistent with previous studies, the addition of ethanol led to a small increase in the maximum CD yield obtained. ${ }^{[18]}$ Previous reports hypothesised that this yield increase might be due to a relatively reduced rate of hydrolysis, compared to CD formation. ${ }^{[17]}$ However, detailed kinetics analysis (Section S7.2 and Figures S17 and S18 in the Supporting Information) revealed an exponential decay in the rates of both hydrolysis and CD formation reactions in the presence of ethanol, as evidenced by the linear correlation between the logarithm of the reaction half-lives and the ethanol content (Figure $5 b$ ). This result is consistent with the observation that our dynamic system develops increasingly more slowly as the ethanol content is increased (time to equilibrium is $<1$ hour in aqueous solution, several hours with $20 \%$ ethanol, 1 day with $30 \%$ ethanol and $>3$ days with $40-50 \%$ ethanol). Our data shows ethanol retards both the $C D$ formation and hydrolysis rates to a similar extent. We propose that the higher maximum $C D$ yield observed in the presence of ethanol is in fact a consequence of ethanol binding to $\alpha-C D$ after it forms and thus 'protecting' this substrate from the action of CGTase by host-guest complex formation.

\section{The influence of high salt content}

Since the hydrophobic effect is thought to be the main driving force for host-guest interactions of CDs, and the hydrophobic effect can be enhanced by addition of chaotropic salts, we were interested to explore the influence of high salt concentrations on our dynamic CD system. Recent reports have indicated that strong interactions can occur between $\mathrm{CDs}$ and chaotropic anions, ${ }^{[21]}$ and $\mathrm{NaNO}_{3}$ has frequently been used in supramolecular systems and DCLs in order to increase hydrophobic effects. ${ }^{[22]}$ We thus prepared and closely monitored a series of CGTase-mediated dynamic CD systems starting from G6 $(10 \mathrm{mg} / \mathrm{mL})$ in phosphate buffer $(40 \mathrm{mM}$ at $\mathrm{pH} 7.5)$ at room temperature in the presence of $0-7.5 \mathrm{M} \mathrm{NaNO}_{3}$.

Remarkably, the enzyme retained its activity at these very high salt concentrations, reaching a steady equilibrium distribution of CDs within 1-3 hours. However, the relative concentrations of $\alpha-, \beta-$, and $\gamma-C D$ obtained at equilibrium was strongly influenced by the presence of salt (Figure 6). A gradual increase in the relative concentration of $\alpha-C D$ from $34 \%$ to $79 \%$ in the presence of $7.5 \mathrm{M} \mathrm{NaNO}_{3}$ was seen accompanied by a concomitant decrease in $\beta-C D$ and $\gamma-C D$ concentration. Although a $7.5 \mathrm{M} \mathrm{NaNO}_{3}$ concentration is equivalent to ca. $46 \%$ by weight in the solvent, and is equivalent to just 5.5 water molecules per $\mathrm{NaNO}_{3}$ moiety, only a modest change in the equilibration time was observed, with the system needing closer to 3 hours to reach equilibrium in the presence of higher concentrations of $\mathrm{NaNO}_{3}$ (Figures S19 and S20 in the Supporting Information). Saltinduced changes in dynamic systems have been observed before ${ }^{[23]}$ but not in a system of uncharged macrocycles such as CDs. Further experiments are underway to determine whether the dynamic system reacts differently to kosmotropic and chaotropic salts. 


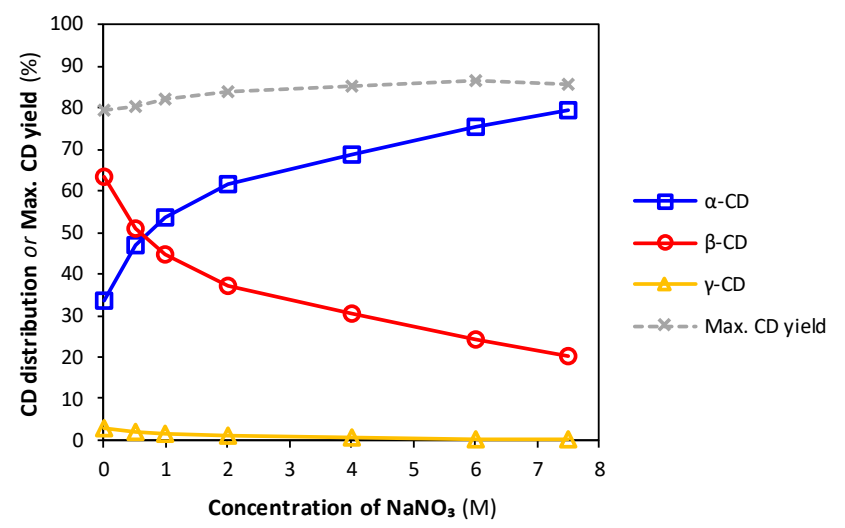

Figure 6. Equilibrium $\mathrm{CD}$ distribution as a function of $\mathrm{NaNO}_{3}$ concentration Conditions: G6 $(10 \mathrm{mg} / \mathrm{mL})$ in sodium phosphate buffer $(40 \mathrm{mM}, \mathrm{pH} 7.5)$ treated with CGTase at room temperature in the presence of the indicated amount of sodium nitrate.

\section{Enhanced template-directed selective synthesis of $\alpha-C D$}

In a previous study exploring the use of templates to selectively synthesise different CDs in our CGTase-mediated DCLs, we could obtain $\beta-C D$ with $>99 \%$ selectivity by adding 1 -adamantane carboxylic acid, and $\gamma-C D$ with $>99 \%$ selectivity by adding tetraphenylborate, but the highest $\alpha-C D$ selectivity we managed to obtain was $89 \%$ using sodium dodecyl sulfate (SDS) as the template. ${ }^{[12 a]}$ Although $\alpha-C D$ was shown to bind 2:1 to SDS with two high affinities $\left(K_{\mathrm{a} 1}\right.$ of $(1.9 \pm 0.5) \cdot 10^{4} \mathrm{M}^{-1}$ and $K_{\mathrm{a} 2}$ of $(2.3 \pm$ $\left.0.4) \cdot 10^{4} \mathrm{M}^{-1}\right)$, the low selectivity was due to a competing strong $1: 1$ binding interaction between SDS and $\beta-\mathrm{CD}\left(K_{\mathrm{a} 1}\right.$ of $(1.6 \pm$ $\left.0.4) \cdot 10^{4} \mathrm{M}^{-1}\right) \cdot{ }^{[12 a]}$ Seeking to improve this result, we sought now to apply our new knowledge of reaction condition influences on the thermodynamics of our cyclodextrin DCL, to enhance the template-directed selective synthesis of $\alpha-C D$.

The entropic penalty $(\Delta S)$ for the formation of a 2:1 complex is larger than for the formation of a similar $1: 1$ complex. Since the magnitude of the entropic contribution to binding free energy change depends on temperature $(\Delta \mathrm{G}=\Delta \mathrm{H}-T \cdot \Delta \mathrm{S})$, it seemed plausible that the $2: 1(\alpha-C D)_{2}$. SDS complex would be relatively favoured over the similar 1:1 CD.SDS complex at lower temperatures, leading to enhanced $\alpha-C D$ production. (Figure $7 a$ ).

We set up and monitored a series of CGTase reactions starting from $\mathbf{G 6}(10 \mathrm{mg} / \mathrm{mL})$ at $\mathrm{pH} 7.5(50 \mathrm{mM}$ sodium phosphate buffer) with $5 \mathrm{mM}$ SDS (the optimal concentration to favour 2:1 binding determined in our previous study $)^{[12 a]}$ in a range of temperatures $\left(5,22\right.$, and $37{ }^{\circ} \mathrm{C}$ ) (Figures S21 and S22 in the Supporting Information). The equilibrium $C D$ distribution as a function of temperature is shown in Figure 7b. As anticipated, $\alpha-$ CD selectivity increased upon lowering the temperature. In fact, at $5{ }^{\circ} \mathrm{C} \alpha-\mathrm{CD}$ was formed with $99 \%$ selectivity and in high yield, which highlights how strategic selection of reaction conditions in these CGTase-mediated DCLs can be exploited to enhance template effects and control the outcome of an enzyme-mediated process.

\section{Conclusions}

In conclusion, we have demonstrated how turning the dials of $\mathrm{pH}$, temperature, concentration and solvent polarity, in the form of adding organic solvents or inorganic salts to the aqueous reaction, allows strategic control over the outcome of the CGTasemediated dynamic cyclodextrin system. These non-template effects can be combined with templates for enhanced control of selectivity. Here we demonstrated how the system can be manipulated so that CGTase generates $\alpha-C D$ as the only significant $C D$ product. Furthermore, the robustness of this system shows that enzyme-mediated dynamic combinatorial chemistry need not be confined to narrow ranges of $\mathrm{pH}$, temperature and solvent compositions. We hope that this study will encourage the further exploration of different reversible enzymatic transformations for the generation of dynamic chemical systems. a

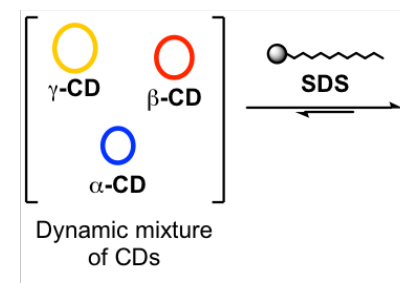

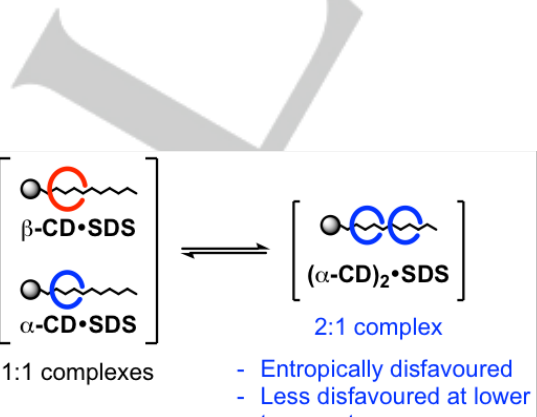

temperature b

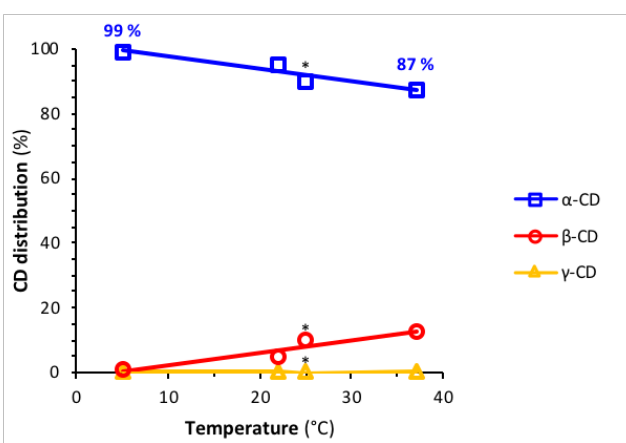

Figure 7. Enhancing $\alpha-C D$ selectivity. (a) Model of the 1:1 complexes and 2:1 complex formed in an enzyme-mediated DCL of CDs when SDS is employed as a template. (b) Equilibrium CD distribution obtained in the presence of SDS as a function of temperature. Conditions: $\mathbf{G 6}$ (10 mg/mL) in sodium phosphate buffer (50 $\mathrm{mM})$ at $\mathrm{pH} 7.5$ treated with CGTase at indicated temperature in presence of SDS $(5 \mathrm{mM})$. Results at $25^{\circ} \mathrm{C}$ from previous study ${ }^{[12 a]}$ are marked with asterisks $\left({ }^{\star}\right)$. 


\section{Acknowledgements}

We are thankful to Amano Enzyme Inc., Nagoya, Japan, for providing a stock solution of CGTase from Bacillus macerans as a kind gift. We gratefully acknowledge the Villum Foundation and the Carlsberg Foundation financial support.

Keywords: Cyclodextrins - Dynamic Combinatorial Chemistry • Enzymes • Host-guest systems • Supramolecular Chemistry

[1] a) P. T. Corbett, J. Leclaire, L. Vial, K. R. West, J. L. Wietor, J. K. M. Sanders, S. Otto, Chem. Rev. 2006, 106, 3652-3711; b) R. A. R. Hunt, S. Otto, Chem. Commun. 2011, 47, 847-858; c) A. Herrmann, Chem. Soc Rev. 2014, 43, 1899-1933; d) M. Mondal, A. K. Hirsch, Chem. Soc. Rev. 2015, 44, 2455-2488; e) P. Frei, R. Hevey, B. Ernst, Chem. Eur. J. 2019, $25,60-73$.

[2] a) S. Ulrich, Acc. Chem. Res. 2019, 52, 510-519; b) Y. Zhang, M. Barboiu, Chem. Rev. 2016, 116, 809-834.

[3] T. Kosikova, D. Philp, Chem. Soc. Rev. 2017, 46, 7274-7305.

[4] a) T. Lizal, L. Ustrnul, M. Necas, V. Sindelar, J. Org. Chem. 2016, 81, 8906-8910; b) M. Lisbjerg, B. M. Jessen, B. Rasmussen, B. E. Nielsen, A. Ø. Madsen, M. Pittelkow, Chem. Sci. 2014, 5, 2647-2650; c) M. von Delius, Synlett 2015, 27, 177-180; d) P. S. Bols, H. L. Anderson, Acc. Chem. Res. 2018, 51, 2083-2092.

[5] a) I. Alfonso, Chem. Commun. 2016, 52, 239-250; b) Y. Liu, J.-M. Lehn, A. K. H. Hirsch, Acc. Chem. Res. 2017, 50, 376-386.

[6] S. P. Black, J. K. M. Sanders, A. R. Stefankiewicz, Chem. Soc. Rev. 2014, 43, 1861-1872.

[7] a) A. Dirksen, S. Dirksen, T. M. Hackeng, P. E. Dawson, J. Am. Chem. Soc. 2006, 128, 15602-15603; b) P. Crisalli, E. T. Kool, J. Org. Chem. 2013, 78, 1184-1189; c) D. Larsen, M. Pittelkow, S. Karmakar, E. T. Kool, Org. Lett. 2015, 17, 274-277.

[8] P. G. Swann, R. A. Casanova, A. Desai, M. M. Frauenhoff, M. Urbancic, U. Slomczynska, A. J. Hopfinger, G. C. Le Breton, D. L. Venton, Pept. Sci. 1996, 40, 617-625.

[9] a) R. J. Lins, S. L. Flitsch, N. J. Turner, E. Irving, S. A. Brown, Angew. Chemie Int. Ed. 2002, 41, 3405-3407; b) R. J. Lins, S. L. Flitsch, N. J. Turner, E. Irving, S. A. Brown, Tetrahedron 2004, 60, 771-780.
[10] R. Castangia, M. Austeri, S. L. Flitsch, Angew. Chemie Int. Ed. 2012, 52, 13016-13018.

[11] a) R. J. Williams, A. M. Smith, R. Collins, N. Hodson, A. K. Das, R. V Ulijn, Nat. Nanotechnol. 2009, 4, 19-24; b) C. G. Pappas, R. Shafi, I. R. Sasselli, H. Siccardi, T. Wang, V. Narang, R. Abzalimov, N. Wijerathne, R. V. Ulijn, Nat. Nanotechnol. 2016, 11, 960-967; c) M. Kumar, N. L. Ing, V. Narang, N. K. Wijerathne, A. I. Hochbaum, R. V. Ulijn, Nat. Chem. 2018, 10, 696-703.

[12] a) D. Larsen, S. R. Beeren, Chem. Sci. 2019, 10, 9981-9987; b) D. Larsen, P. M. Bjerre, S. R. Beeren, Chem. Commun. 2019, 55, $15037-$ 15040.

[13] a) J. Szejtli, Chem. Rev. 1998, 98, 1743-1753; b) K. A. Connors, Chem. Rev. 1997, 97, 1325-1357; c) M. V Rekharsky, Y. Inoue, Chem. Rev. 1998, 98, 1875-1918.

[14] a) E. M. M. Del Valle, Proc. Biochem. 2004, 39, 1033-1046; b) T. Loftsson, M. E. Brewster, J. Pharm. Pharmacol. 2010, 62, 1607-1621.

[15] a) A. Biwer, G. Antranikian, E. Heinzle, Appl. Microbiol. Biotechnol. 2002, 59, 609-617; b) [1] Z. Li, M. Wang, F. Wang, Z. Gu, G. Du, J. Wu, J. Chen, Appl. Microbiol. Biotechnol. 2007, 77, 245-255; c) S. Kobayashi, in Prog. Biotechnol. (Eds.: J.F.R. Kwan-Hwa Park, C. Yang-Do), Elsevier, 1996, pp. 23-41.

[16] a) P. T. Corbett, S. Otto, J. K. M. Sanders, Chem. - A Eur. J. 2004, 10, 3139-3143; b) A. T. Ten Cate, P. Y. W. Dankers, R. P. Sijbesma, E. W. Meijer, J. Org. Chem. 2005, 70, 5799-5803.

[17] Q. Qi, M. N. Mokhtar, W. Zimmermann, J. Incl. Phenom. Macrocycl. Chem. 2007, 57, 95-99.

[18] a) A. D. Blackwood, C. Bucke, Enzyme Microb. Technol. 2000, 27, 704708; b) L. P. Calsavara, A. R. Dias da Cunha, T. A. Balbino, G. M. Zanin, F. F. de Moraes, Appl Biochem Biotechnol 2011, 165, 1485-1493.

[19] H. Fujiwara, H. Arakawa, S. Murata, Y. Sasaki, Bull. Chem. Soc. Jpn. 1987, 60, 3891-3894.

[20] R. F. Ludlow, J. Liu, H. Li, S. L. Roberts, J. K. Sanders, S. Otto, Angew. Chemie Int. Ed. Engl. 2007, 46, 5762-5764.

[21] a) K. I. Assaf, M. S. Ural, F. Pan, T. Georgiev, S. Simova, K. Rissanen, D. Gabel, W. M. Nau, Angew. Chemie Int. Ed. Engl. 2015, 54, 68526856; b) K. I. Assaf, D. Gabel, W. Zimmermann, W. M. Nau, Org. Biomol. Chem. 2016, 14, 7702-7706; c) K. I. Assaf, W. Nau, Angew. Chemie Int. Ed. 2018, 57, 13968-13981.

[22] a) H. Y. Au-Yeung, G. D. Pantos, J. K. M. Sanders, Proc. Natl. Acad. Sci. U. S. A. 2009, 106, 10466-10470; b) J. H. Jordan, B. C. Gibb, Chem. Soc. Rev. 2015, 44, 547-585.

[23] J. Atcher, A. Moure, J. Bujons, I. Alfonso, Chem. - A Eur. J. 2015, 21, 6869-6878. 
WILEY-VCH

Entry for the Table of Contents (Please choose one layout)

Layout 1:

\section{ARTICLE}

Tuning in to enzyme-mediated dynamic systems. CGTase-mediated dynamic combinatorial libraries of cyclodextrins can be established at wide ranges of $\mathrm{pH}$, temperature, solvent composition and salinity. Control of these conditions determines which cyclodextrins are preferentially produced. Combining the influence of reaction conditions with known template effects allows us to produce $\alpha-C D$ with remarkably high selectivity.

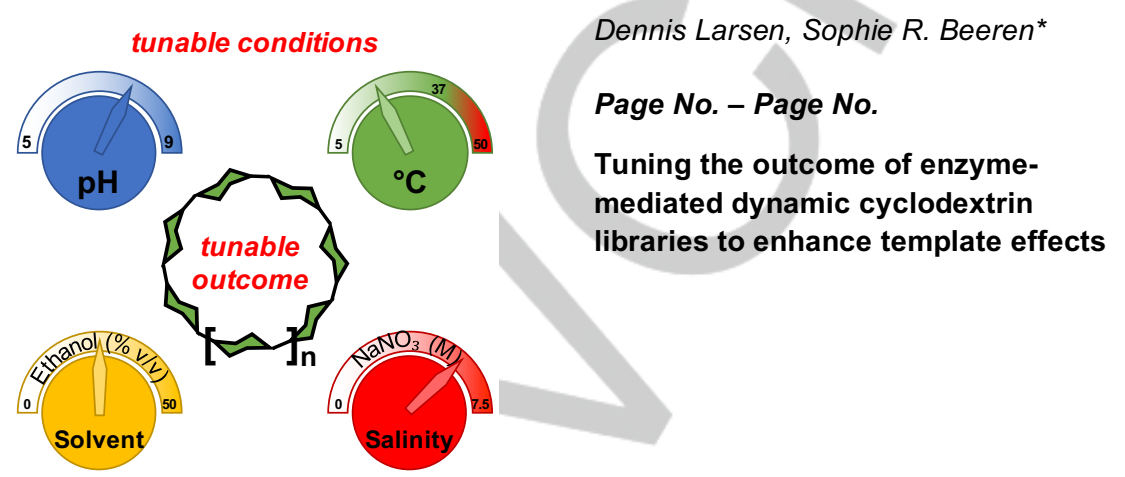

